\title{
Association Between Obesity-Related Dyspnea in Daily Living, Lung Function and Body Composition Analyzed by DXA: A Prospective Study of 130 Patients
}

\section{Jean Hagenburg}

CHU Reims: Centre Hospitalier Universitaire de Reims

\section{Eric Bertin}

CHU Reims: Centre Hospitalier Universitaire de Reims Jean-Hugues Salmon

CHU Reims: Centre Hospitalier Universitaire de Reims Aurore Thierry

CHU Reims: Centre Hospitalier Universitaire de Reims Jeanne-Marie Perotin

CHU Reims: Centre Hospitalier Universitaire de Reims

\section{Valerian Dormoy}

INSERM-UMR S 1250

\section{Sandra Dury}

CHU Reims: Centre Hospitalier Universitaire de Reims

\section{Lois Bolko}

CHU Reims: Centre Hospitalier Universitaire de Reims

\section{François Lebargy}

CHU Reims: Centre Hospitalier Universitaire de Reims

\section{Gaetan Deslee}

CHU Reims: Centre Hospitalier Universitaire de Reims

Claire Launois ( $\nabla$ claunois@chu-reims.fr)

CHU Reims: Centre Hospitalier Universitaire de Reims https://orcid.org/0000-0002-6429-666X

\section{Research}

Keywords: dyspnea, obesity, lung function, body composition, Dual-energy X-ray absorptiometry

Posted Date: September 7th, 2021

DOI: https://doi.org/10.21203/rs.3.rs-847326/v1 
License: (c) (i) This work is licensed under a Creative Commons Attribution 4.0 International License. Read Full License

Version of Record: A version of this preprint was published at BMC Pulmonary Medicine on March 25th, 2022. See the published version at https://doi.org/10.1186/s12890-022-01884-5. 


\section{Abstract}

\section{Background}

Obesity is a risk factor for dyspnea. However, investigations of daily living obesity-related dyspnea are limited and its mechanisms remain unclear. We aimed to analyze the relationships between dyspnea in daily living, lung function, and body composition in patients with obesity.

\section{Methods}

One-hundred and thirty patients (103 women/27 men), candidate for bariatric surgery, with a mean \pm SD Body Mass Index (BMI) of $44.8 \pm 6.8 \mathrm{~kg} / \mathrm{m}^{2}$ were included. Dyspnea was assessed by the modified Medical Research Council (mMRC) scale. Comorbidities, laboratory parameters, pulmonary function tests, arterial blood gases, six-minute walk test (6MWT), handgrip strength, and DXA body composition were analyzed.

\section{Results}

Thirty-one percent of patients exhibited disabling dyspnea in daily living ( $\mathrm{mMRC} \geq 2)$. Compared with patients without disabling dyspnea $(\mathrm{mMRC}<2)$, significant dyspnea $(\mathrm{mMRC} \geq 2)$ was associated with a lower 6MWT distance (395 $\pm 103 \mathrm{~m}$ vs $457 \pm 73 \mathrm{~m}, p<0.001)$ ), lower lung volumes including Expiratory Reserve Volume ( $42 \pm 28 \%$ vs $54 \pm 27 \%, p=0.024)$, Vital Capacity $(95 \pm 14$ vs $106 \pm 15 \%, p<0.001)$ and Forced expiratory volume in one second ( $95 \pm 13$ vs $105 \pm 15 \%, p=0.002)$, a higher BMI (48.2 \pm 7.7 vs 43.2 $\left.\pm 5.7 \mathrm{~kg} / \mathrm{m}^{2}, p=0.001\right)$ and a higher percentage of fat mass in the trunk (46 $\left.\pm 5 \mathrm{vs} 44 \pm 5 p=0.012\right)$ and android region ( $52 \pm 4$ vs $51 \pm 4 \%, p=0.024$ ). There was no difference regarding comorbidities (except hypertension), laboratory parameters, and sarcopenia markers between patients with (mMRC $\geq 2)$ and without $(\mathrm{mMRC}<2)$ disabling dyspnea.

\section{Conclusion}

Dyspnea in patients with obesity is associated with a reduction in lung volumes and a higher percentage of fat mass in central body regions. How dyspnea and body composition may change with interventions like physical activity or bariatric surgery remains to be investigated.

\section{Trial Registration}

Reims University Hospital Institutional Review Board (IRB-17-10-2012).

\section{Background}

Although obesity is a significant risk factor for dyspnea (1-3), daily living obesity-related dyspnea has been the primary focus of a small number of studies (4-7). While obesity has long been recognized as having significant effects on lung function (8), the mechanisms of obesity-related dyspnea remain 
unclear. In patients with obesity, lung volumes tend to be decreased (9) and maximal inspiratory pressure (MIP) can also be low, reflecting decreased inspiratory muscle performance $(10,11)$. Previous studies with relatively small population samples have shown that these abnormalities are moderately associated with daily living dyspnea in obese patients (4-7).

Associations between obesity and impaired skeletal muscle quality, poor physical performance, and a higher risk of sarcopenia have been well-established (12). Dyspnea may also reduce physical activity as in chronic respiratory disease (13), subsequently leading to limb muscle impairment and deconditioning.

Body mass index (BMI) is the most commonly used measure to characterize obesity but is limited by its assessment of body weight relative to height, with no information on the body composition per se. Dualenergy X-ray absorptiometry (DXA) is a quick, weakly radiating, and reliable tool allowing to accurately measure body composition and to determine specific sites of fat deposition (14). Regarding the effects of body fat distribution on lung function, DXA studies have shown that body fat deposition in the central regions (both thorax and abdomen) was associated with lung volume decrease (15). These findings have been attributed to the restriction and load imposed by the excess fat mass on the thoracic cage and abdomen, placing the diaphragm, the main inspiratory muscle, into an inefficient position. Nevertheless, to our knowledge, the relationships between obesity-related dyspnea and body composition assessed by DXA have not been investigated so far.

The main objective of this study was to assess the relationships between dyspnea in daily living according to MMRC, lung function and body composition assessed by DXA in patients with obesity. We hypothesized that patients with disabling dyspnea would have a higher BMI and a higher proportion of fat mass, especially in the central regions of the body. The secondary objectives were to analyze the relationships between dyspnea in daily living and sarcopenia assessed by appendicular lean mass and handgrip strength measurements. We also investigated relationships between dyspnea, comorbidities, and laboratory parameters.

\section{Methods}

\section{Patients and design}

Between January 2017 to February 2020, consecutive adult patients with obesity referred to the Department of Nutrition at the University Hospital of Reims (France) for a project of bariatric surgery were systematically evaluated for dyspnea, lung function tests, handgrip strength, and body composition. All patients were included in the study before bariatric surgery, except those with a known respiratory, cardiac, or neuromuscular disease. Patients were also excluded if they did not perform the different investigations in a maximal period of two months.

Written information was provided, and each patient gave his consent to participate. The study was approved by the Reims University Hospital Institutional Review Board (IRB-17-10-2012). 


\section{Clinical characteristics and dyspnea assessment}

Demographic data (age, sex), anthropometric characteristics (size, weight, BMI), medical comorbidities (hypertension, diabetes, dyslipidemia, severe obstructive sleep apnea syndrome (OSAS), defined as an Apnea-Hypopnea Index $>30 / \mathrm{h}$ ), medical treatments (antihypertensive drugs, oral antidiabetics, insulin, cholesterol-lowering agents) and smoking status were systematically recorded.

The depression symptoms were assessed using the QD2A depression scale $(16,17)$. This tool is a 13item self-rated questionnaire of depressive symptomatology. Each item presents a statement that the subject answers as "true" or "false", and the score is the number of items the subject marked "true" and varies from 0 to 13. A score of 7 or more indicates depression.

Dyspnea in daily living was evaluated using the $\operatorname{mMRC}$ scale $(5,18,19)$. This scale consists of five statements that almost entirely describe the range of dyspnea from none (grade 0 ) to almost complete incapacity (grade 4) (Table 1). The mMRC is the most commonly used validated scale to assess dyspnea in daily living in chronic respiratory diseases and a mMRC score $\geq 2$ is considered as disabling dyspnea (18).

Table 1

Modified Medical Research Council (mMRC) dyspnea scale

Grade of
dyspnea

\begin{tabular}{|ll|}
\hline 0 & I only get breathless with strenuous exercise \\
\hline 2 & I get short of breath when hurrying on level ground or walking up a slight hill \\
\hline 3 & $\begin{array}{l}\text { On level ground, I walk slower than people of the same age because of } \\
\text { breathlessness, } \\
\text { or I have to stop for breath when walking at my own pace on the level }\end{array}$ \\
\hline 4 & $\begin{array}{l}\text { I stop for breath after walking about } 100 \text { yards or after a few minutes on level } \\
\text { I am too breathless to leave the house or I am breathless when dressing }\end{array}$ \\
\hline
\end{tabular}

\section{Muscle strength}

Measurement of handgrip strength was conducted in a standardized manner by the use of a handgrip dynamometer type JAMAR (Saehan ${ }^{\circledR}$ Hydraulic Hand Dynamometer model SH 5001, Korea) in neutral rotation and adducted position of the shoulder, with the elbow flexed to 90 degrees, and forearm and wrist in a neutral position. Three trials from the dominant hand were measured in kilograms. The mean value was considered for the analyses. Grip strength less than $16 \mathrm{~kg}$ for women and less than $27 \mathrm{~kg}$ for men were considered low handgrip strength $(20,21)$.

\section{Lung function tests}




\section{Six-minute walk test}

The six-minute walk test (6MWT) was performed in a 30-meter long, flat, covered corridor, marked meterby-meter, according to the American Thoracic Society guidelines (22). Oxygen saturation and modified Borg scale subjectively assessing the degree of dyspnea graded from 0 to 10 were collected at the beginning and the end of the 6MWT. The distance covered was calculated at the end of the test.

\section{Arterial blood gases}

Arterial Blood Gases were measured in the morning in a sitting position on room air.

\section{Pulmonary function testing}

PFTs were performed according to the American Thoracic Society/European Respiratory Society guidelines (23) (BodyBox 5500 Medisoft Sorinnes, Belgium). Vital capacity (VC), forced vital capacity $(\mathrm{FVC})$, forced expiratory volume in one second $\left(\mathrm{FEV}_{1}\right), \mathrm{FEV}_{1} / \mathrm{FVC}$ ratio, expiratory reserve volume (ERV) were measured during spirometry. Residual volume (RV), functional residual capacity (FRC), and total lung capacity (TLC) were measured during plethysmography. As the plethysmography cabin is not suitable for patients weighing more than $150 \mathrm{~kg}$, spirometric measurements only (including $\mathrm{FEV}_{1}, \mathrm{VC}$, $\mathrm{FVC}, \mathrm{FEV}_{1} / \mathrm{FVC}$, and ERV) were performed in patients weighing more than $150 \mathrm{~kg}$. Results are expressed in milliliters and percentage of predicted values. The carbon monoxide diffusing capacity of the lung (DLCO) was measured and expressed in percentage of predicted values.

\section{Evaluation of inspiratory and expiratory muscle strength}

Respiratory muscle strength consisted of measuring Maximal Inspiratory Pressure (MIP) and Maximal Expiratory Pressure (MEP). The maximum value of three available tests that varied by less than $20 \%$ was recorded. Results were expressed in $\mathrm{cmH} 2 \mathrm{O}$ and percentage of predicted values (24).

\section{Laboratory parameters}

Hemoglobin $(\mathrm{Hb}), \mathrm{C}$ reactive protein (CRP), and N-terminal prohormone of brain natriuretic peptide (NTpro-BNP) were determined from a blood sample.

\section{Body composition assessment}

Body composition was determined by DXA scan (Hologic Horizon ${ }^{\text {TM }}$ DXA System QDR®, Vilvoorde, Belgium). DXA was quantified by the body tissue absorption of photons that were emitted at two energy levels to resolve body weight into bone mineral density (BMD), lean (LM), and fat (FM) soft tissue masses (25). $F M(\mathrm{~kg}), B M D+L M(k g)$, and FM percentage (\%) for standard body regions, such as the trunk, lower limbs, android, and gynoid regions delineated by specific anatomical landmarks were analyzed. The trunk region was defined as the region horizontally below the chin, with vertical borders lateral to the ribs and oblique lines through the femoral neck. The lower limb region was defined as the region under the oblique lines through the femoral necks and within the leg lines. Android and gynoid regions were selected as regions of interest $(\mathrm{ROI})$ using the software provided by the manufacturer. Briefly, the android ROI was 
defined as a portion of the abdomen included between the line joining the two superior iliac crests (lower boundary) and extending cranially up to $20 \%$ of the distance between this line and the chin. The gynoid ROI upper boundary was defined as 1.5 times the height of the android ROI below the iliac crest to a line equal to twice the height of the android ROI (lower boundary). As some patients ( $n=45)$ exceeded the scan area dimensions concerning the arms, whole body, and upper limbs region data were not analyzed. Appendicular lean mass index (ALMI) was calculated as the sum of the lean mass of both the upper (when available) and the lower limbs adjusted for height $\left(\mathrm{m}^{2}\right)$ (or as the sum of the lean mass of an upper limb in whole included in the scan multiplied by 2 and lower limbs adjusted for height $\left.\left(\mathrm{m}^{2}\right)\right)(26)$. Sarcopenic obesity was defined according to Baumgartner et al. (27) as ALMI $<7.26 \mathrm{~kg} / \mathrm{m}^{2}$ in men and $5.45 \mathrm{~kg} / \mathrm{m}^{2}$ in women.

\section{Statistical analysis}

Quantitative variables were described as mean \pm standard deviation (SD) and qualitative variables as number and percentage. Patients were separated into two groups according to their mMRC dyspnea scale: $m M R C<2$ (no disabling dyspnea in daily living) and $m M R C \geq 2$ (disabling dyspnea in daily living). Variables associated with mMRC scale were studied using Wilcoxon or Fisher exact tests. A p-value $<0.05$ was considered statistically significant.

\section{Results}

\section{Patient characteristics}

One-hundred and seventy-three consecutive patients were included in the study. Thirty-two of them were excluded because of an inability to perform PFTs and/or DXA and eleven because of an interval longer than two months between respiratory assessment and DXA. The data of the remaining 130 patients (103 women and 27 men) were analyzed. Of note, 111 patients (85\%) performed respiratory assessment and DXA on the same day.

Clinical, anthropometric, and demographic characteristics of the patients are presented in Table 2 . The mean BMI was $44.8 \pm 6.8 \mathrm{~kg} / \mathrm{m}^{2}$ and the mean Android/Gynoid fat mass ratio was $1.09 \pm 0.09$.

Overall, pulmonary function tests remained in the normal range for most of the patients except for ERV

(577 $\pm 395 \mathrm{~mL}, 50 \pm 28 \%$ ). Regarding inspiratory and expiratory muscle strength, MIP was $61 \pm 27 \mathrm{cmH}_{2} \mathrm{O}$ $(70 \pm 31 \%)$ and MEP was $73 \pm 36 \mathrm{cmH}_{2} \mathrm{O}(66 \pm 30 \%)$. 
Table 2

Clinical and demographic characteristics of the 130 obese patients.

\begin{tabular}{|c|c|c|c|}
\hline & $\begin{array}{l}\text { Patients } \\
(n=130)\end{array}$ & $\begin{array}{l}\text { Women } \\
(n=103)\end{array}$ & $\begin{array}{l}\text { Men } \\
(n=27)\end{array}$ \\
\hline Age (years) & $42( \pm 11)$ & $42( \pm 11)$ & $42( \pm 11)$ \\
\hline Size (cm) & $167( \pm 8)$ & $164( \pm 6)$ & $178( \pm 6)$ \\
\hline Weight (kg) & $124.6( \pm 22.2)$ & $119.2( \pm 19.5)$ & $145.2( \pm 20.2)$ \\
\hline BMI $\left(\mathrm{kg} / \mathrm{m}^{2}\right)$ & $44.8( \pm 6.8)$ & $44.4( \pm 6.6)$ & $46.0( \pm 7.2)$ \\
\hline \multicolumn{4}{|l|}{ Comorbidities } \\
\hline Hypertension & $44(34 \%)$ & $30(29 \%)$ & $14(52 \%)$ \\
\hline Diabetes & $24(18 \%)$ & $16(16 \%)$ & $8(30 \%)$ \\
\hline Dyslipidemia & $19(15 \%)$ & $11(11 \%)$ & $8(30 \%)$ \\
\hline Severe OSAS & $36(28 \%)$ & $21(21 \%)$ & $15(56 \%)$ \\
\hline \multicolumn{4}{|l|}{ Treatments } \\
\hline Antihypertensive drugs & $38(29 \%)$ & $27(26 \%)$ & $11(42 \%)$ \\
\hline Oral antidiabetics & $22(17 \%)$ & $15(15 \%)$ & $7(26 \%)$ \\
\hline Insulin & $11(8 \%)$ & $7(7 \%)$ & $4(15 \%)$ \\
\hline Cholesterol-lowering agents & $8(6 \%)$ & $5(5 \%)$ & $3(12 \%)$ \\
\hline \multicolumn{4}{|l|}{ Smoking history $(\mathrm{n}=103)$} \\
\hline Current & $13(28 \%)$ & $8(28 \%)$ & $5(29 \%)$ \\
\hline Former & $33(32 \%)$ & $21(27 \%)$ & $12(50 \%)$ \\
\hline Never & $56(54 \%)$ & $49(62 \%)$ & $7(30 \%)$ \\
\hline Pack-Years & $16( \pm 15)$ & $11( \pm 10)$ & $25( \pm 20)$ \\
\hline \multicolumn{4}{|c|}{ Data are expressed as mean ( \pm SD) or number (\%). } \\
\hline \multicolumn{4}{|c|}{$p$ for the comparison between women and men } \\
\hline$*: p<0.05 ; * *: p<0.001$ & & & \\
\hline
\end{tabular}


Table 3

Dyspnea assessment of the 130 obese patients.

\begin{tabular}{|c|c|c|c|c|}
\hline & $\begin{array}{l}\text { Patients } \\
(n=130)\end{array}$ & Women $(n=103)$ & $\begin{array}{l}\text { Men } \\
(n=27)\end{array}$ & $p$ \\
\hline \multicolumn{5}{|l|}{ mMRC scale (/4) } \\
\hline $\mathrm{mMRC} \geq 1$ & $96(74 \%)$ & $76(74 \%)$ & $\begin{array}{l}20 \\
(74 \%)\end{array}$ & 1 \\
\hline $\mathrm{mMRC} \geq 2$ & $40(31 \%)$ & $29(28 \%)$ & $\begin{array}{l}11 \\
(41 \%)\end{array}$ & 0.244 \\
\hline \multicolumn{5}{|c|}{ Borg scale $(/ 10)(n=119)$} \\
\hline Borg at rest $\geq 1$ & $13(11 \%)$ & $12(13 \%)$ & $1(4 \%)$ & 0.463 \\
\hline Borg after $6 \mathrm{MWT} \geq 1$ & $106(89 \%)$ & $84(88 \%)$ & $\begin{array}{l}22 \\
(92 \%)\end{array}$ & 1 \\
\hline Borg after $6 \mathrm{MWT} \geq 5$ & $38(32 \%)$ & $30(32 \%)$ & $8(33 \%)$ & 1 \\
\hline \multicolumn{5}{|c|}{ Data are expressed as mean $( \pm S D)$ or number $(\%)$} \\
\hline \multicolumn{5}{|c|}{$p$ for the comparison between women and men } \\
\hline \multicolumn{5}{|c|}{ Abbreviations: mMRC: modified Medical Research Council; 6MWT: six-minute walk tes } \\
\hline
\end{tabular}

Comparisons of clinical parameters, lung function tests, and laboratory parameters between patients with $m M R C<2$ and patients with $m M R C \geq 2$

There were no statistically significant differences between patients with $(\mathrm{mMRC} \geq 2)$ and without $(\mathrm{mMRC}$ $<2$ ) disabling dyspnea regarding treatments $(23 \%$ vs $14 \%, p=0.312$ for oral antidiabetics; $13 \%$ vs $7 \%, p=$ 0.312 for insulin; $5 \%$ vs $7 \%, p=1$ for cholesterol-lowering agents; $38 \%$ vs $26 \%, p=0.148$ for antihypertensive drugs) and comorbidities ( $25 \%$ vs $16 \%, p=0.225$ for diabetes; $18 \%$ vs $13 \%, p=0.594$ for dyslipidemia; $36 \%$ vs 25\%, $p=0.207$ for severe OSAS) except for hypertension ( $48 \%$ vs $28 \%, p=0.044$ ). No significant difference was found regarding the depression state according to the QD2A depression scale ( $9 \%$ in patients with $m M R C<2(n=6) v s 11 \%$ in patients with $m M R C \geq 2$ group $(n=3), p=0.720)$. The percentage of active smokers $(22 \%$ vs $56 \%, p=0.092)$ and the number of pack-years $(15 \pm 14 v s 21 \pm$ $22, p=0.512$ ) were similar in the two groups of patients.

Compared with patients with $m M R C<2$, patients who experienced disabling dyspnea $(m M R C \geq 2)$ had a lower 6MWT distance and a significant reduction in lung volumes (Table 4). 
Table 4

Comparison of 6-minute walk test, arterial blood gases, pulmonary function tests and laboratory parameters between patients with $\mathrm{mMRC}<2$ and patients with $\mathrm{mMRC} \geq 2$.
$\mathrm{mMRC}<2$
$\mathrm{mMRC} \geq 2$
$(n=90)$
$(n=40)$

$p$

6-minute walk test $(n=119)$

6-minute walk test distance $(\mathrm{m})$

$457( \pm 73)$

$395( \pm 103)$

0.0006 **

Sp02 at rest (\%)

$98( \pm 1)$

$96( \pm 6)$

0.073

Sp02 after 6MWT (\%)

$94( \pm 3)$

$94( \pm 3)$

0.577

Borg at rest (/10)

$0.15( \pm 0.36)$

$0.38( \pm 0.89)$

0.422

Borg after 6MWT (/10)

$3.33( \pm 2.12)$

$4.65( \pm 2.69)$

$0.014^{*}$

Arterial blood gases $(n=124)$

$\mathrm{pH}$

$7.42( \pm 0.02)$

$7.41( \pm 0.03)$

0.312

$\mathrm{PaO}_{2}(\mathrm{mmHg})$

$93( \pm 13)$

$94( \pm 17)$

0.663

$\mathrm{PaCO}_{2}(\mathrm{mmHg})$

$37( \pm 3)$

$37( \pm 4)$

0.770

$\mathrm{HCO}_{3}{ }^{-}\left(\mathrm{mmol} . \mathrm{L}^{-1}\right)$

$23( \pm 2)$

$23( \pm 2)$

0.465

\section{Pulmonary function tests}

Spirometry $(n=130)$

\begin{tabular}{llll} 
VC $(\mathrm{mL})$ & $3766( \pm 847)$ & $3362( \pm 799)$ & $\mathbf{0 . 0 0 5 *}$ \\
\hline VC $(\%$ pred $)$ & $106( \pm 15)$ & $95( \pm 14)$ & $\mathbf{0 . 0 0 0 7 * *}$ \\
\hline FVC $(\mathrm{mL})$ & $3729( \pm 843)$ & $3324( \pm 812)$ & $\mathbf{0 . 0 0 6 *}$ \\
\hline FVC $(\%$ pred $)$ & $105( \pm 15)$ & $95( \pm 13)$ & $\mathbf{0 . 0 0 2 *}$ \\
\hline FEV $(\mathrm{mL})$ & $3032( \pm 657)$ & $2646( \pm 597)$ & $\mathbf{0 . 0 0 0 8 *}$ \\
\hline FEV $_{1}(\%$ pred $)$ & $100( \pm 15)$ & $90( \pm 15)$ & $\mathbf{0 . 0 0 0 4 * *}$
\end{tabular}

Data are expressed as mean ( \pm SD) or number (\%).*: $p<0.05 ; * *: p<0.001$

Abbreviations: mMRC: modified Medical Research Council; 6MWT: six-minute walk test; Sp02: Pulse Oxygen Saturation; PaO2: Partial arterial pressure of oxygen, $\mathrm{PaCO} 2$ : Partial arterial pressure of carbon dioxide; HCO3-: bicarbonate anion; VC: Vital capacity; FVC: Forced vital capacity; FEV $_{1}$ : Forced expiratory volume in one second; ERV: Expiratory reserve volume; RV: Residual volume; FRC:

Functional residual capacity; TLC: Total lung capacity; DLCO: Diffusing capacity of the lung for carbon monoxide; MIP: Maximal inspiratory pressure; MEP: Maximal expiratory pressure; CRP: Creactive protein; NT-pro-BNP: N-terminal prohormone of brain natriuretic peptide 


\begin{tabular}{|c|c|c|c|}
\hline & $\begin{array}{l}\mathrm{mMRC}<2 \\
(\mathrm{n}=90)\end{array}$ & $\begin{array}{l}m M R C \geq 2 \\
(n=40)\end{array}$ & $p$ \\
\hline $\mathrm{FEV}_{1} / \mathrm{FVC}(\%$ pred $)$ & $82( \pm 6)$ & $80( \pm 7)$ & 0.362 \\
\hline $\mathrm{ERV}(\mathrm{mL})$ & $627( \pm 404)$ & $464( \pm 353)$ & $0.024^{*}$ \\
\hline ERV (\% pred) & $54( \pm 27)$ & $42( \pm 28)$ & $0.014^{*}$ \\
\hline \multicolumn{4}{|l|}{ Plethysmography $(n=110)$} \\
\hline $\mathrm{RV}(\mathrm{mL})$ & $2069( \pm 668)$ & $1832( \pm 710)$ & 0.336 \\
\hline RV (\% pred) & $122( \pm 33)$ & $110( \pm 36)$ & 0.197 \\
\hline $\mathrm{FRC}(\mathrm{mL})$ & $2719( \pm 641)$ & $2841( \pm 739)$ & 0.127 \\
\hline FRC (\% pred) & $97( \pm 20)$ & $88( \pm 22)$ & $0.0504^{*}$ \\
\hline $\mathrm{TLC}(\mathrm{mL})$ & $5760( \pm 1023)$ & $5225( \pm 1133)$ & $0.033^{*}$ \\
\hline TLC (\% pred) & $109( \pm 16)$ & $99( \pm 16)$ & $0.0036 *$ \\
\hline DLCO (\% pred) & $90( \pm 15)$ & $85( \pm 20)$ & 0.166 \\
\hline \multicolumn{4}{|c|}{ Inspiratory muscle strength $(\mathrm{n}=127)$} \\
\hline $\operatorname{MIP}\left(\mathrm{cmH}_{2} \mathrm{O}\right)$ & $63( \pm 29)$ & $56( \pm 21)$ & 0.358 \\
\hline MIP (\% pred) & $73( \pm 33)$ & $64( \pm 25)$ & 0.189 \\
\hline \multicolumn{4}{|c|}{ Expiratory muscle strength $(n=127)$} \\
\hline $\operatorname{MEP}\left(\mathrm{cmH}_{2} \mathrm{O}\right)$ & $73( \pm 37)$ & $74( \pm 36)$ & 0.888 \\
\hline MEP (\% pred) & $67( \pm 30)$ & $66( \pm 30)$ & 0.907 \\
\hline \multicolumn{4}{|c|}{ Laboratory parameters $(n=103)$} \\
\hline Hemoglobin $(\mathrm{g} / \mathrm{L})$ & $135( \pm 13)$ & $132( \pm 14)$ & 0.245 \\
\hline $\mathrm{CRP}(\mathrm{mg} / \mathrm{L})$ & $8.5( \pm 7.8)$ & $10.7( \pm 9.7)$ & 0.193 \\
\hline NT-pro-BNP > 50 (pg/mL) & $15(22 \%)$ & $8(29 \%)$ & 0.601 \\
\hline \multicolumn{4}{|c|}{ Data are expressed as mean $( \pm S D)$ or number $(\%) . *: p<0.05 ; \star \star: p<0.001$} \\
\hline \multicolumn{4}{|c|}{$\begin{array}{l}\text { Abbreviations: mMRC: modified Medical Research Council; } 6 \mathrm{MWT} \text { : six-minute walk test; } \mathrm{SpO} \text { 2: Pulse } \\
\text { Oxygen Saturation; PaO2: Partial arterial pressure of oxygen, PaCO2: Partial arterial pressure of } \\
\text { carbon dioxide; HCO3-: bicarbonate anion; VC: Vital capacity; FVC: Forced vital capacity; FEV } 1 \text { : Forced } \\
\text { expiratory volume in one second; ERV: Expiratory reserve volume; RV: Residual volume; FRC: } \\
\text { Functional residual capacity; TLC: Total lung capacity; DLCO: Diffusing capacity of the lung for } \\
\text { carbon monoxide; MIP: Maximal inspiratory pressure; MEP: Maximal expiratory pressure; CRP: C- } \\
\text { reactive protein; NT-pro-BNP: N-terminal prohormone of brain natriuretic peptide }\end{array}$} \\
\hline
\end{tabular}


Comparison of body composition between patients with $\mathrm{mMRC}<2$ and $\mathrm{mMRC} \geq 2$

Comparisons of body composition between patients without $(\mathrm{mMRC}<2)$ and with disabling dyspnea $(m M R C \geq 2)$ are presented in Table 5. Patients with disabling dyspnea $(m M R C \geq 2)$ had a higher BMl, a higher mass, and a higher fat mass whatever the analyzed body segment (trunk, lower limbs, android, and gynoid regions) than patients with $\mathrm{mMRC}<2$. They also had a higher percentage of fat mass in the trunk and the android region than patients with $m M R C<2$. There was no difference in sarcopenia markers (handgrip strength and appendicular lean mass index) between these 2 groups of patients. 
Table 5

Comparison of body composition between patients with $\mathrm{mMRC}<2$ and patients with $m M R C \geq 2$.

\begin{tabular}{|c|c|c|c|}
\hline & $\begin{array}{l}\mathrm{mMRC}<2 \\
(\mathrm{n}=90)\end{array}$ & $\begin{array}{l}m M R C \geq 2 \\
(n=40)\end{array}$ & $p$ \\
\hline Size $(\mathrm{cm})$ & $167( \pm 9)$ & $166( \pm 8)$ & 0.723 \\
\hline Weight (kg) & $120.9( \pm 20.7)$ & $133.0( \pm 23.5)$ & $0.0052 *$ \\
\hline BMI $\left(\mathrm{kg} / \mathrm{m}^{2}\right)$ & $43.2( \pm 5.7)$ & $48.2( \pm 7.7)$ & $0.001 *$ \\
\hline \multicolumn{4}{|l|}{ Hand grip dynamometer $(n=112)$} \\
\hline Hand grip strength $(\mathrm{kg})$ & $27( \pm 9)$ & $28( \pm 10)$ & 0.853 \\
\hline Low hand grip strength ${ }^{\mp}$ & $5(7 \%)$ & $3(8 \%)$ & 1 \\
\hline \multicolumn{4}{|l|}{ Dual X-ray Absorptiometry } \\
\hline Low ALMI $^{\mp \mp}(n=85)$ & $0(0 \%)$ & $0(0 \%)$ & 1 \\
\hline \multicolumn{4}{|l|}{ Trunk } \\
\hline Mass (kg) & $55.58( \pm 10.90)$ & $61.33( \pm 13.08)$ & $0.017 *$ \\
\hline$\%$ total body mass & $47( \pm 5)$ & $47( \pm 4)$ & 0.719 \\
\hline LM-BMD (kg) & $31.16( \pm 5.52)$ & $32.69( \pm 5.70)$ & 0.117 \\
\hline $\mathrm{FM}(\mathrm{kg})$ & $24.42( \pm 6.39)$ & $28.64( \pm 8.79)$ & $0.008 *$ \\
\hline FM (\%) & $44( \pm 5)$ & $46( \pm 5)$ & $0.012^{*}$ \\
\hline \multicolumn{4}{|l|}{ Lower limbs } \\
\hline Mass (kg) & $39.68( \pm 7.10)$ & $43.83( \pm 7.93)$ & $0.004^{*}$ \\
\hline$\%$ total body mass & $33( \pm 3)$ & $33( \pm 3)$ & 0.970 \\
\hline LM-BMD (kg) & $20.45( \pm 4.23)$ & $21.94( \pm 4.56)$ & 0.055 \\
\hline $\mathrm{FM}(\mathrm{kg})$ & $19.22( \pm 4.51)$ & $21.89( \pm 5.31)$ & $0.014^{*}$ \\
\hline $\mathrm{FM}(\%)$ & $48( \pm 6)$ & $50( \pm 6)$ & 0.175 \\
\hline \%FM Trunk/\% FM Lower limbs & $0.91( \pm 0.13)$ & $0.93( \pm 13)$ & 0.288 \\
\hline \multicolumn{4}{|l|}{ Android } \\
\hline Mass (kg) & $10.14( \pm 2.34)$ & $11.60( \pm 2.56)$ & $0.002^{*}$ \\
\hline$\%$ total body mass & $8( \pm 1)$ & $9( \pm 1)$ & $0.021^{*}$ \\
\hline LM-BMD (kg) & $4.97( \pm 1.16)$ & $5.49( \pm 1.12)$ & $0.012^{*}$ \\
\hline
\end{tabular}




\begin{tabular}{|llll|}
\hline & $\begin{array}{l}\text { mMRC }<2 \\
(\mathbf{n}=90)\end{array}$ & $\begin{array}{l}\text { mMRC } \geq 2 \\
(\mathbf{n}=40)\end{array}$ & $\boldsymbol{p}$ \\
\hline FM $(\mathrm{kg})$ & $5.17( \pm 1.30)$ & $6.12( \pm 1.60)$ & $\mathbf{0 . 0 0 1 *}$ \\
\hline FM (\%) & $51( \pm 4)$ & $52( \pm 4)$ & $\mathbf{0 . 0 2 4 *}$ \\
\hline Gynoid & & & \\
\hline Mass $(\mathrm{kg})$ & $18.69( \pm 3.46)$ & $20.42( \pm 3.52)$ & $\mathbf{0 . 0 0 9 *}$ \\
\hline \% total body mass & $16( \pm 1)$ & $16( \pm 1)$ & 0.713 \\
\hline LM-BMD (kg) & $9.88( \pm 1.97)$ & $10.47( \pm 2.03)$ & 0.098 \\
\hline FM (kg) & $8.81( \pm 2.00)$ & $9.95( \pm 2.08)$ & $\mathbf{0 . 0 0 9 *}$ \\
\hline FM (\%) & $47( \pm 5)$ & $49( \pm 5)$ & 0.074 \\
\hline Android/gynoid fat mass ratio & $1.09( \pm 9)$ & $1.09( \pm 9)$ & 0.821 \\
\hline
\end{tabular}

Data are expressed as mean $( \pm S D)$ or number $(\%)$.

$*: p<0.05 ; * \star: p<0.001$

Abbreviations: mMRC: modified Medical Research Council; BMI: Body mass index; ALMI: Appendicular lean mass index; TM: Total mass; FM: Fat mass; LM: Lean mass; BMD: Bone mineral density

${ }^{\mp}$ : hand grip strength was considered low when $<16 \mathrm{~kg}$ in women and $<27 \mathrm{~kg}$ in men; ${ }^{\mp \mp}$ : ALMI was considered low when $<5.45 \mathrm{~kg} / \mathrm{m}^{2}$ in women and $<7.26 \mathrm{~kg} / \mathrm{m}^{2}$ in men

Daily living dyspnea according to mMRC scale depending on BMI

Depending on BMI grouped according to World Health Organization categories $(28,29)$, the percentage of patients with $\mathrm{mMRC} 0, \mathrm{mMRC} 1$, and $\mathrm{mMRC} \geq 2$ was significantly different $(p=0.031)$ as well as the percentage of patients with $m M R C<2$ and $m M R C \geq 2(p=0.006)$ (Fig. 1).

\section{Discussion}

This study analyzed the relationships between dyspnea in daily living, lung function, and body composition assessed by DXA in obese patients and demonstrates that disabling dyspnea in daily living was associated with lower lung volumes and 6MWT distance, and a higher BMI and fat mass, especially in the central regions of the body. 
In large cohorts, $80 \%$ of obese adults experience dyspnea after climbing two flights of stairs (30) and approximately one-third of obese adults report dyspnea when walking up a hill (1). Obese adults are also twice as likely as adults with normal BMI to have dyspnea mMRC score $\geq 2$ (3). The prevalence of dyspnea in our cohort was similar to previous studies with about three-quarters of the patients experiencing dyspnea in daily living $(\mathrm{mMRC} \geq 1)$ and more than a third describing disabling dyspnea in daily living ( $m M R C$ score $\geq 2$, i.e. walk slower than people of the same age on level ground) and severe dyspnea on exertion (Borg $\geq 5$ after 6MWT) $(5,6)$. Interestingly, there was no difference in dyspnea severity between men and women in this study.

Dyspnea encompasses an array of unpleasant respiratory sensations that vary according to the underlying cause and patient characteristics. Psychological state (especially comorbid anxiety and depression) could modify the perception of dyspnea (31). In this study, demographic characteristics, medical comorbidities except for hypertension, QD2A depression score, and smoking status were similar between patients with and without disabling dyspnea in daily living according to the mMRC dyspnea scale.

As expected, patients with disabling dyspnea in daily living ( $\mathrm{MMRC} \geq 2)$, who had also higher $\mathrm{BMI}$ and fat mass than patients with $\mathrm{mMRC}<2$, covered a lower distance during the 6MWT than patients with $\mathrm{mMRC}<2(5)$.

It is well known that obesity causes substantial changes to the mechanics of the lungs and chest wall that affect lung function. The most frequent abnormality associated with obesity is a decrease in ERV, which is exponentially correlated with increased BMI (9). While obesity significantly reduces ERV and consequently FRC (FRC = ERV + RV), it has very little effect on VC and TLC (9). RV is typically within the normal range in the presence of obesity. Other dynamic measures of lung function such as $\mathrm{FEV}_{1}$ and $\mathrm{FVC}$ are slightly reduced in people with obesity (32), but FEV $1 / F V C$ ratio is usually unaffected. We found similar results concerning lung function in this cohort of obese patients, showing that patients with disabling dyspnea in daily living ( $\mathrm{MMRC} \geq 2$ ), who had also higher $\mathrm{BMI}$, had a significant reduction in measures of lung function affected by obesity (VC, FVC, FEV1, ERV, FRC, TLC).

Effects of obesity on inspiratory and expiratory muscle strength are variable and inconsistent $(10,11,33)$. Respiratory muscle function might be impaired by a myopathy or by the load imposed on the diaphragm by obesity itself. Contrary to Collet et al (4), we did not find a significant association between disabling dyspnea and inspiratory muscle strength. A possible explanation is that respiratory muscle strength is assessed by volitional methods and the patient's motivation and effort can affect the results.

Despite the absence of consensus on the definition of sarcopenic obesity, it is commonly accepted as the combination of obesity and muscle impairment, either defined by low muscle mass and/or poor muscle strength/function. In a large cohort from the National Health and Nutrition Surveys, the prevalence of sarcopenic obesity is $17 \%$ in obese patients aged 60 to 70 years (34). In our study, patients 
were younger with no patient exhibiting a low appendicular lean mass and very few patients with low handgrip strength. Furthermore, there was no association between these variables assessing muscle impairment and the presence of disabling dyspnea.

Disabling dyspnea according to $\mathrm{mMRC}$ was associated with an increase in weight, $\mathrm{BMI}$, and fat mass in absolute value for all body segments. Interestingly, patients with disabling dyspnea also presented an increase in the percentage of fat mass for the central regions of the body: trunk and android region. Sutherland et al. also showed that both thoracic and abdominal body fat had an impact on lung volumes (15). In our study, patients with disabling dyspnea had also lower lung volumes. Taken together, these data support the hypothesis that dyspnea may be mediated by the deposition of adipose tissue around the thorax restricting expansion, and/or by abdominal adiposity impeding diaphragmatic excursion.

Our results have several clinical implications. First, it provides clinicians with a glimpse of the dyspnea endured by obese patients especially in patients with high and very high BMI (Figure 1). Second, there is a significant effect of adiposity on dyspnea and this relationship is robust regardless of the adiposity measurement (BMI, weight, fat mass in all analyzed body segments). Thus, assessing the effect of adiposity on dyspnea may be adequately undertaken using a simple measurement, such as BMI, in clinical practice.

One of the strengths of our study is the assessment of the relationships between dyspnea according to the mMRC scale, a very complete respiratory assessment (6MWT, arterial blood gases, PFTs, inspiratory and expiratory muscle strength), laboratory parameters, depression scale, and body composition assessed by DXA. Our results highlight a significant association between the presence of disabling dyspnea, reduction in lung volumes, and increase in BMI and fat mass, especially in the central region of the body which is known to be associated with lung volume reduction. Nevertheless, the body composition and the fat mass repartition are probably not the only predictors of dyspnea in patients with obesity. Several other factors such as anxiety $(35,36)$ may be involved in dyspnea perception in patients with obesity and were not analyzed in this study. This study has several other limitations. First, it was conducted in a single center, which may limit the generalizability of the results. Second, the study cohort included only candidates for bariatric surgery (predominantly women, relatively young) and consequently does not reflect the whole population of obese individuals. Moreover, our study does not provide information regarding the effects of interventions like bariatric surgery. It has been shown that bariatric surgery improves dyspnea in about two-thirds of patients (6). As body composition significantly changes after bariatric surgery with reduced whole-body and regional fat mass and especially decreased percentage of android fat mass (37), it would be interesting to study the relationships between body composition modification and dyspnea improvement after bariatric surgery.

\section{Conclusion}


This prospective study showed that dyspnea in daily living in obese patients is associated with a reduction in lung volumes and higher BMl, possibly related to a higher percentage of fat mass in central body regions. It remains to be investigated how dyspnea and body composition may change with interventions like physical activity or bariatric surgery.

\section{Abbreviations}

6MWT: Six-minute walk test

ALMI: Appendicular lean mass index

ATS: American Thoracic Society

BMD: Bone mineral density

BMI: Body mass index

CRP: C-reactive protein

DLCO: Carbon monoxide diffusing capacity of the lung

DXA: Dual-energy X-ray Absorptiometry

ERV: Expiratory reserve volume

$\mathrm{FEV}_{1}$ : Forced expiratory volume in one second

FM: Fat mass

FRC: Functional residual capacity

FVC: Forced vital capacity

$\mathrm{Hb}$ : Hemoglobin

LM: Lean mass

MEP: Maximal expiratory pressure

MIP: Maximal inspiratory pressure

mMRC: Modified Medical Research Council dyspnea scale

NT-pro-BNP: N-terminal prohormone of brain natriuretic peptide 
OSAS: Obstructive sleep apnea syndrome

PFTs: Pulmonary function tests

ROI: Regions of interest

\section{Declarations}

\section{Ethics approval and consent to participate}

Written information was provided, and each patient gave his consent to participate. The study was approved by the Reims University Hospital Institutional Review Board (IRB-17-10-2012).

\section{Consent for publication}

Not applicable.

\section{Availability of data and materials}

The datasets during and/or analysed during the current study available from the corresponding author on reasonable request.

\section{Competing interests}

The authors declare that they have no competing interests.

\section{Funding}

_This research did not receive any specific grant from funding agencies in the public, commercial, or not-for-profit sectors.

\section{$\underline{\text { Authors' contributions }}$}

$\mathrm{JH}, \mathrm{GD}$ and $\mathrm{CL}$ designed the study. JH, EB, JHS, JMP, SD, LB, FL, GD and CL were involved in the data collection. AT performed the statistical analysis. JH and CL drafted the manuscript. All authors analyzed and interpreted data, read and approved the final manuscript.

\section{Acknowledgements}

We would like to thank the personnel of the Departements of Nutrition, Rheumatology, and Pulmonary Medicine for the clinical/functional assessment of the patients.

\section{References}

1. Sin DD, Jones RL, Man SFP. Obesity is a risk factor for dyspnea but not for airflow obstruction. Arch Intern Med. 8 juill 2002;162(13):1477-81. 
2. Currow DC, Plummer JL, Crockett A, Abernethy AP. A community population survey of prevalence and severity of dyspnea in adults. J Pain Symptom Manage oct. 2009;38(4):533-45.

3. Currow DC, Dal Grande E, Sidhu C, Ekström M, Johnson MJ. The independent association of overweight and obesity with breathlessness in adults: a cross-sectional, population-based study. Eur Respir J. 2017;50(3):1700558.

4. Collet F, Mallart A, Bervar JF, Bautin N, Matran R, Pattou F, et al. Physiologic correlates of dyspnea in patients with morbid obesity. Int J Obes (Lond) avr. 2007;31(4):700-6.

5. Launois C, Barbe C, Bertin E, Nardi J, Perotin J-M, Dury S, et al. Research Council scale for the assessment of dyspnea in daily living in obesity: a pilot study. BMC Pulm Med. oct 2012;1:12:61.

6. Boissière L, Perotin-Collard J-M, Bertin E, Gaubil I, Diaz Cives A, Barbe C, et al. Improvement of dyspnea after bariatric surgery is associated with increased Expiratory Reserve Volume: A prospective follow-up study of 45 patients. PLoS ONE. 2017;12(9):e0185058.

7. Teixeira CA, Dos Santos JE, Silva GA, de Souza EST, Martinez JAB. Prevalence of and the potential physiopathological mechanisms involved in dyspnea in individuals with class II or III obesity. J Bras Pneumol févr. 2007;33(1):28-35.

8. Littleton SW. Impact of obesity on respiratory function. Respirology janv. 2012;17(1):43-9.

9. Jones RL, Nzekwu M-MU. The effects of body mass index on lung volumes. Chest sept. 2006;130(3):827-33.

10. Chlif M, Keochkerian D, Choquet D, Vaidie A, Ahmaidi S. Effects of obesity on breathing pattern, ventilatory neural drive and mechanics. Respir Physiol Neurobiol. sept 2009;30(3):198-202. 168(.

11. Arena R, Cahalin LP. Evaluation of cardiorespiratory fitness and respiratory muscle function in the obese population. Prog Cardiovasc Dis févr. 2014;56(4):457-64.

12. Batsis JA, Villareal DT. Sarcopenic obesity in older adults: aetiology, epidemiology and treatment strategies. Nat Rev Endocrinol. 2018;14(9):513-37.

13. O’Donnell DE, James MD, Milne KM, Neder JA. The Pathophysiology of Dyspnea and Exercise Intolerance in Chronic Obstructive Pulmonary Disease. Clin Chest Med. 2019;40(2):343-66.

14. Seabolt LA, Welch EB, Silver HJ. Imaging methods for analyzing body composition in human obesity and cardiometabolic disease. Ann N Y Acad Sci sept. 2015;1353:41-59.

15. Sutherland TJT, Goulding A, Grant AM, Cowan JO, Williamson A, Williams SM, et al. The effect of adiposity measured by dual-energy X-ray absorptiometry on lung function. Eur Respir J juill. 2008;32(1):85-91.

16. Pichot P, Boyer P, Pull CB, Rein W, Simon M. Un questionnaire d'auto-évaluation de la symptomatologie dépressive, le questionnaire QD2. II: Forme abrégée QD2A. Revue de psychologie appliquée (Paris). 1984;34(4):323-40.

17. Pichot $P$, et al. Un questionnaire d'auto-évaluation de la symptomatologie dépressive, le Questionnaire QD2: I. Construction, structure factorielle et propriétés métrologiques. [A questionnaire 
for self-evaluation of depressive symptomatology, the QD2 Questionnaire: I. Construction, factorial structure and metrological properties.]. Revue de Psychologie Appliquée. 1984;34(3):229-50.

18. Bestall JC, Paul EA, Garrod R, Garnham R, Jones PW, Wedzicha JA. Usefulness of the Medical Research Council (MRC) dyspnoea scale as a measure of disability in patients with chronic obstructive pulmonary disease. Thorax juill. 1999;54(7):581-6.

19. Gerlach Y, Williams MT, Coates AM. Weighing up the evidence - a systematic review of measures used for the sensation of breathlessness in obesity. Int J Obes (Lond) mars. 2013;37(3):341-9.

20. Cruz-Jentoft AJ, Bahat G, Bauer J, Boirie Y, Bruyère O, Cederholm T, et al. Sarcopenia: revised European consensus on definition and diagnosis. Age Ageing 1 janv. 2019;48(1):16-31.

21. Donini LM, Busetto L, Bauer JM, Bischoff S, Boirie Y, Cederholm T, et al. Critical appraisal of definitions and diagnostic criteria for sarcopenic obesity based on a systematic review. Clin Nutr août. 2020;39(8):2368-88.

22. ATS Committee on Proficiency Standards for Clinical Pulmonary Function Laboratories. ATS statement: guidelines for the six-minute walk test. Am J Respir Crit Care Med 1 juill. 2002;166(1):111-7.

23. Culver BH, Graham BL, Coates AL, Wanger J, Berry CE, Clarke PK, et al. Recommendations for a Standardized Pulmonary Function Report. An Official American Thoracic Society Technical Statement. Am J Respir Crit Care Med. 1 déc 2017;196(11):1463-72.

24. American Thoracic Society/European Respiratory Society. ATS/ERS Statement on respiratory muscle testing. Am J Respir Crit Care Med 15 août. 2002;166(4):518-624.

25. Imboden MT, Welch WA, Swartz AM, Montoye AHK, Finch HW, Harber MP, et al. Reference standards for body fat measures using GE dual energy x-ray absorptiometry in Caucasian adults. PLoS ONE. 2017;12(4):e0175110.

26. Silva AM, Heymsfield SB, Sardinha LB. Assessing body composition in taller or broader individuals using dual-energy X-ray absorptiometry: a systematic review. Eur J Clin Nutr oct. 2013;67(10):101221.

27. Baumgartner RN, Wayne SJ, Waters DL, Janssen I, Gallagher D, Morley JE. Sarcopenic obesity predicts instrumental activities of daily living disability in the elderly. Obes Res déc. 2004;12(12):1995-2004.

28. Obesity. preventing and managing the global epidemic. Report of a WHO consultation. World Health Organ Tech Rep Ser. 2000;894:i-xii, 1-253.

29. Renquist K. Obesity classification. Obes Surg août. 1998;8(4):480.

30. Sjöström L, Larsson B, Backman L, Bengtsson C, Bouchard C, Dahlgren S, et al. Swedish obese subjects (SOS). Recruitment for an intervention study and a selected description of the obese state. Int J Obes Relat Metab Disord juin. 1992;16(6):465-79.

31. Marines-Price R, Bernhardt V, Bhammar DM, Babb TG. Dyspnea on exertion provokes unpleasantness and negative emotions in women with obesity. Respir Physiol Neurobiol. 2019;260:131-6. 
32. Leone N, Courbon D, Thomas F, Bean K, Jégo B, Leynaert B, et al. Lung function impairment and metabolic syndrome: the critical role of abdominal obesity. Am J Respir Crit Care Med. 15 mars 2009;179(6):509-16.

33. Kelly TM, Jensen RL, Elliott CG, Crapo RO. Maximum respiratory pressures in morbidly obese subjects. Respiration. 1988;54(2):73-7.

34. Batsis JA, Mackenzie TA, Emeny RT, Lopez-Jimenez F, Bartels SJ. Low Lean Mass With and Without Obesity, and Mortality: Results From the 1999-2004 National Health and Nutrition Examination Survey. J Gerontol A Biol Sci Med Sci. oct 2017;1(10):1445-51. 72(.

35. Stoeckel MC, Esser RW, Gamer M, Büchel C, von Leupoldt A. Dyspnea catastrophizing and neural activations during the anticipation and perception of dyspnea. Psychophysiology. 2018;55(4):e13004.

36. Stoeckel MC, Esser RW, Gamer M, von Leupoldt A. Breathlessness amplifies amygdala responses during affective processing. Psychophysiology sept. 2018;55(9):e13092.

37. Bazzocchi A, Ponti F, Cariani S, Diano D, Leuratti L, Albisinni U, et al. Visceral fat and body composition changes in a female population after RYGBP: a two-year follow-up by DXA. Obes Surg mars. 2015;25(3):443-51.

\section{Figures}




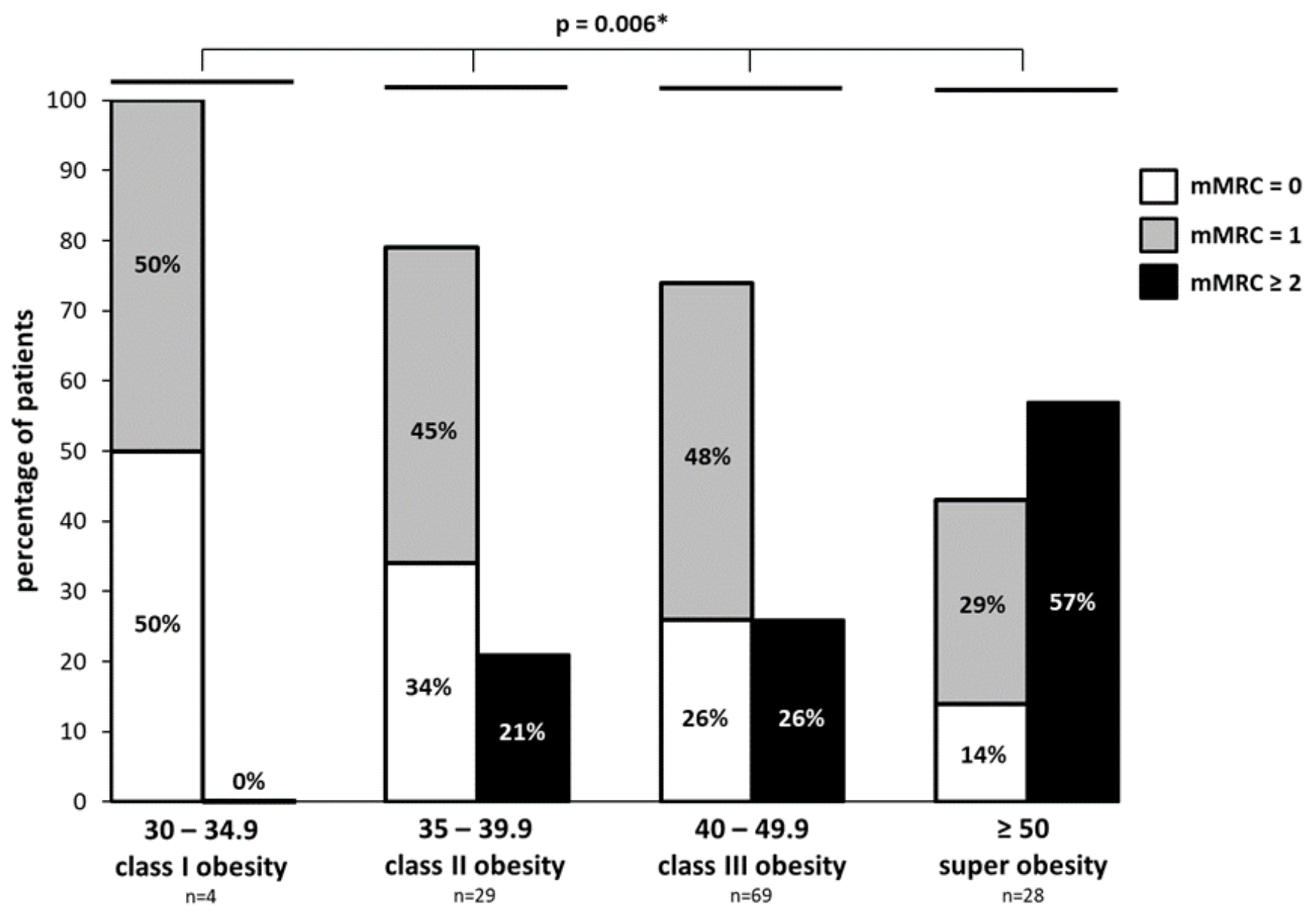

BMI $\left(\mathrm{kg} / \mathrm{m}^{2}\right)$ grouped according to WHO categories

Figure 1

Daily living dyspnea according to $\mathrm{MMRC}$ scale depending on $\mathrm{BMI}$ grouped according to WHO categories Abbreviations: BMI: Body mass index; WHO: World Health Organization; mMRC: modified Medical Research Council *: $p<0.05$ 